\title{
GERENCIAMENTO DE RISCOS NO PROCESSO PRODUTIVO DA BATERIA DE COQUE
}

\section{ARTIGO ORIGINAL}

OLIVEIRA, Bruno Fonseca de ${ }^{1}$

SILVEIRA, Camila Aparecida Maciel da ${ }^{2}$

OLIVEIRA, Bruno Fonseca de. SILVEIRA, Camila Aparecida Maciel da. Gerenciamento de riscos no processo produtivo da Bateria de Coque. Revista Científica Multidisciplinar Núcleo do Conhecimento. Ano 06, Ed. 01, Vol. 01, pp. 3448. Janeiro de 2021. ISSN: 2448-0959, Link de acesso: https://www.nucleodoconhecimento.com.br/engenharia-mecanica/bateriade-coque

\section{RESUMO}

O alto custo do coque no mercado mundial fez com que as siderurgias analisassem a importância da produção interna. Para alcançar a qualidade desejada do coque é preciso que as portas de operação dos fornos estejam totalmente vedadas. Este trabalho visa solucionar um problema oriundo do processo de produção de uma Bateria de Coque. Durante a destilação do carvão é gerado um subproduto denominado alcatrão, que se acumula nas portas de operação passando a não ter total vedação. A substância cria também pontos de passagem de gás para a atmosfera, o que pode causar danos aos componentes mecânicos e criar um passivo ambiental de alto risco para a saúde dos colaboradores. O desenvolvimento desse estudo de caso se baseia nos métodos de gerenciamento de projetos do PMBOK,

${ }^{1}$ Graduado em Engenharia Mecânica, Pós-Graduado em Engenharia de Projetos Mecânicos, MBA em Gerenciamento de Projetos.

${ }^{2}$ Orientadora. Mestrado em Engenharia de Produção. Graduação em Engenharia de Produção. 
sendo de natureza aplicada e abordagem qualitativa. De acordo com o gerenciamento dos riscos a proposta mais adequada é a implantação de um equipamento automatizado de limpeza de portas, por meio de jato de água de alta pressão combinado com raspagem mecânica que realizará a remoção do alcatrão em todo perímetro da porta, permitindo o completo contato entre as partes e assim total estanqueidade do forno.

Palavras-chave: Bateria de coque, limpeza de porta, gerenciamento de riscos.

\section{INTRODUÇÃO}

As usinas siderúrgicas possuem duas principais matérias-primas, o minério de ferro e o coque. A carga de minério de ferro é processada na sinterização e o coque é obtido pelas Baterias de Coque, através do processo de destilação do carvão mineral. Após esses tratamentos, ambos são utilizados nos altos-fornos onde é produzido o ferrogusa, que é transformado em aço nos conversores da aciaria.

O coque metalúrgico é produzido através da destilação de uma determinada mistura de carvões minerais. Essa mistura de carvões, é determinada diante da necessidade do processo, qualidade e custo. O processo de produção do coque, basicamente consiste na transferência de calor das paredes refratárias dos fornos para a mistura de carvões minerais num ambiente totalmente isolado com pressão positiva, sem a presença de oxigênio.

O alcatrão é um produto inerente ao processo de produção do coque siderúrgico, que durante o ciclo de coqueificação do carvão se fixa nas portas operacionais dos fornos causando um problema crítico no seu isolamento. Pela necessidade de os fornos serem hermeticamente isolados, os operadores de produção precisam interromper suas atividades para que manualmente possam realizar a remoção do alcatrão das portas operacionais. O objetivo deste trabalho é propor uma solução para o problema que o alcatrão causa no processo produtivo. 


\section{GERENCIAMENTO DE RISCOS}

O Diagrama de Bow-tie ilustra o perigo, suas causas e consequências e os controles para minimizar o risco. O método para construir um diagrama de Bow-tie envolve fazer um conjunto estruturado de perguntas em sequência lógica. Pesquisas realizadas em oficinas, provaram que o diagrama é uma maneira eficaz de mapear os riscos. Para incentivar a correta identificação dos riscos, o processo de análise precisa ser executado de forma correta e se possível com o auxílio de um facilitador independente (LEWIS, 2005).

Segundo Barboza (2018), o diagrama da gravata "Bowtie" é uma ferramenta de levantamento de riscos simples de ser utilizada por ser visual, de fácil entendimento e que representa de forma eficaz o risco, proporcionando uma oportunidade para identificar e avaliar as principais barreiras de segurança existentes ou ausentes entre um evento de segurança e um resultado inseguro.

A matriz de risco, ou mapa de riscos, é considerada um dos mais efetivos instrumentos de visão geral do risco e seu gerenciamento (PADOVEZE, 2009). Por meio de um mapeamento mais específico e objetivo das ameaças existentes na organização, é possível aferir de maneira mais clara os indícios de um possível problema ou a identificação de um percalço já existente, fazendo a separação desses prováveis ou recorrentes fatos em dois grupos. Os denominados riscos existentes e em operação e os riscos que vão existir (PADOVEZE, 2010).

Ramos (2009) e Rovai (2005) explanam que devem também ser observados a probabilidade e o impacto dos riscos identificados e mensurados anteriormente. $\mathrm{O}$ método de análise de probabilidade e impacto expõe critérios para marcar pontos para os riscos, apontando valores para baixa, média e alta probabilidade e impacto e também da contagem que determina a gravidade de cada um.

A matriz de riscos (Figura 1) apresenta a classificação dos riscos conforme a probabilidade e o impacto, os riscos que forem classificados como alto (cor vermelha) devem receber maior atenção do que os riscos classificados como moderado ou 
médio (cor amarela) e, consequentemente, os riscos classificados como baixo (cor verde) são os que requerem menor atenção.

Figura 1: Matriz de riscos.

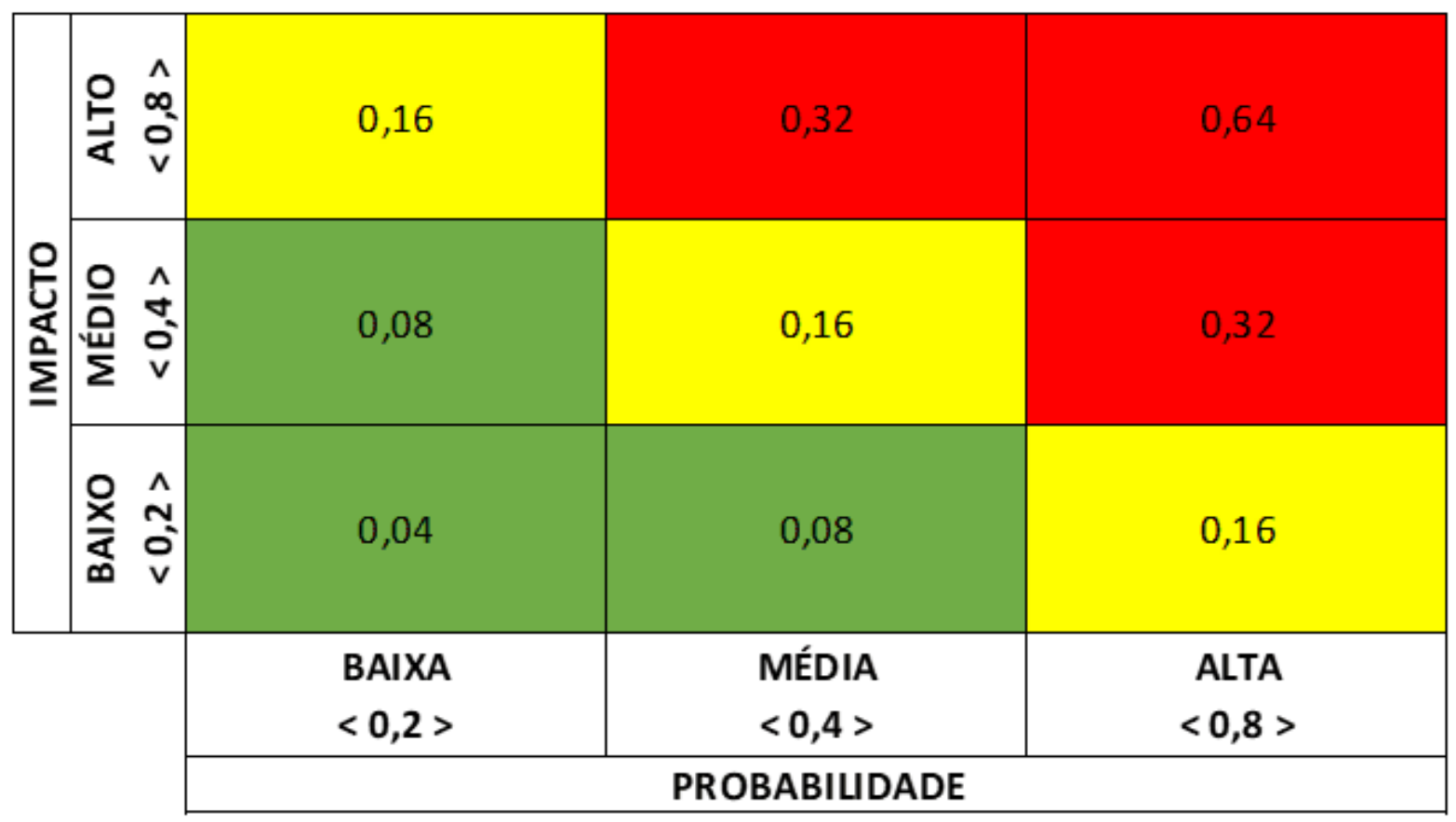

Fonte: Autor (2020).

Por meio da multiplicação dos valores de probabilidade e impacto, pode-se calcular os riscos, por exemplo, alto impacto $(0,8)$ com média probabilidade $(0,4)$, seria: $0,8 \times$ $0,4=0,32$. O risco admitido é caracterizado como alto.

\section{METODOLOGIA}

Este artigo é caracterizado por ser de natureza aplicada, pois a pesquisa busca gerar conhecimento para aplicação prática. O problema possui abordagem qualitativa, sendo um estudo de caso. $O$ objeto de estudo desta pesquisa é a porta de operação da coqueria de uma empresa siderúrgica e a fonte de coleta de dados foram documentos internos disponibilizados, sendo uma pesquisa documental. Com base nas informações obtidas, os pesquisadores analisaram o processo e identificaram os riscos existentes. Foi utilizada também a pesquisa bibliográfica com base em artigos científicos e diante das informações coletadas foram propostas soluções que 
auxiliassem no alcance do objetivo proposto. Para compreensão da metodologia utilizada, apresenta-se as etapas da pesquisa:

$1^{\circ}$ etapa - Análise dos documentos disponibilizados pela empresa sobre o processo analisado com informações sobre os riscos existentes nas etapas analisadas;

$2^{\circ}$ etapa - Pesquisa bibliográfica para conhecer os estudos já realizados sobre a gerenciamento de riscos aplicados a situações reais das indústrias;

$3^{\circ}$ etapa - Levantamento e análise de riscos por meio do Diagrama Bowtie;

$4^{\circ}$ etapa - Mapeamento dos riscos por meio da Matriz de Riscos; e

$5^{\circ}$ etapa - Proposta de soluções para minimização dos riscos e alcance de melhorias.

\section{ESTUDO DE CASO}

\subsection{O PROCESSO PRODUTIVO DO COQUE}

A transformação do carvão em coque ocorre com o calor transferido das paredes de tijolos refratários aquecidos para o carvão. Com cerca de $375^{\circ} \mathrm{C}$ a $475^{\circ} \mathrm{C}$, o carvão se decompõe plasticamente a cada parede. Em cerca de $475^{\circ} \mathrm{C}$ a $600^{\circ} \mathrm{C}$, há uma decomposição do alcatrão e compostos de hidrocarbonetos aromáticos, seguido pela ressolidificação da massa plástica em semi coque. Com $600^{\circ} \mathrm{C}$ a $1100^{\circ} \mathrm{C}$, a fase de estabilização do coque começa. Esta fase é caracterizada pela contração da massa de coque, desenvolvimento estrutural e evolução final do hidrogênio. Durante o estágio de plastificação, as camadas de plástico se movem de cada parede em direção ao centro do forno, liberando e criando um aumento de pressão do gás que é transferido para a parede de aquecimento. Depois que as camadas de plástico se encontram no centro do forno, a massa inteira é carbonizada (HARDARSHAN, 2014).

O carvão vegetal era fabricado, empilhando-se madeira a fazer um monte, depois cobrindo-se este monte com terra e deixando-o arder numa combustão parcial. O carvão resultante era vendido e utilizado como um combustível limpo e sem produzir 
fumo, com os fins mais diversos. Ao contrário do que acontece com o carvão vegetal, a natureza agressiva do fumo formado na combustão do carvão, tornou a utilização do carvão no uso doméstico pouco atrativa.

No entanto, já aproximadamente no ano 1600 a demanda de carvão vegetal tinha deixado marcas de escassez de madeira. De fato, nessa altura já existiam zonas áridas onde anteriormente havia florestas, porque a demanda comercial de carvão tinha aumentado em relação à madeira. Com base neste desenvolvimento foram feitas várias tentativas para se derivar um produto combustível que arde sem fumo com origem no carvão.

Os arquivos mostram que as tentativas mais antigas para obter carvão de coque, foram efetuadas muitas vezes de modo semelhante ao modo como se produzia o carvão vegetal, isto é, empilhavam-se uma quantidade de carvão de forma a fazer um monte, após cobriam-se com terra e queimavam-se gradualmente sob a exclusão parcial do ar. A chave da produção do coque (Figura 2) a partir do carvão é a mesma que a do carvão vegetal, isto é, utilizar sobretudo o calor para expulsar as substâncias voláteis, resultando somente um carvão relativamente puro.

Figura 2: Sequencial logístico macro de produção do coque.

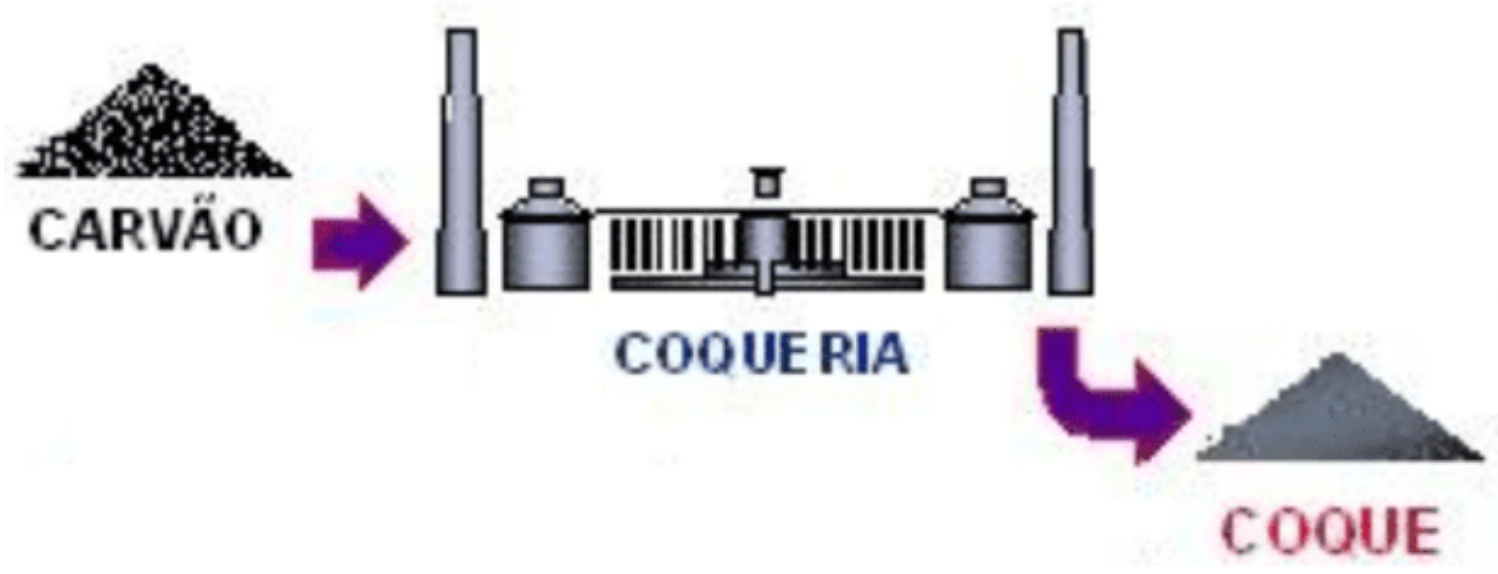

Fonte: Intranet Usiminas (2020). 
Sequencial logístico macro apresentado na Figura 1 pode ser detalhado nas seguintes etapas:

a) Transporte de carvão: O método mais eficaz de transporte do carvão é através das linhas ferroviárias, devido ao grande volume e necessidade da alta velocidade de reposição de estoque.

b) Cambagem: Após a chegada do trem com o carvão na planta siderúrgica, os vagões se acoplam a um equipamento chamado "Virador de vagões", que faz a cambagem do carvão a uma "Correia transportadora".

c) Empilhamento do carvão: As correias transportadoras transportam o carvão até a máquina móvel chamada "Staker", que por sua vez faz o empilhamento do carvão em "grandes montes" no Pátio de Carvão.

d) Retomada do carvão: Para retomada do carvão desses "grandes montes" e posterior transporte para as baterias de coque, é utilizada a máquina móvel chamada "Reclaimer".

e) Correia transportadora: o Reclaimer, faz a retomada do carvão e o dispensa em uma correia transportadora, para transporte do carvão do Pátio de Carvão para os Silos de Carvão, já na Bateria de Coque.

f) Silos de carvão: Os silos de carvão fazem a armazenagem temporária do carvão para posterior distribuição igualitária nos silos das máquinas móveis chamadas "Enfornadoras".

g) Enfornamento: $O$ enfornamento é realizado pela máquina móvel "Enfornadora" que recepciona o carvão dos "Silos de Carvão", transportam até o forno e o abastecem.

h) Coqueificação: Após o abastecimento do forno, de acordo com os parâmetros de coqueificação determinados pela necessidade produtiva, o carvão mineral passa a se tornar o coque. 
i) Desenfornamento: Após o período de coqueificação do carvão, o coque é retirado de dentro do forno através da máquina móvel chamada "Desenfornadora".

\subsection{DESCRIÇÃO DO CENÁRIO}

Durante o processo de coqueificação e consequente decomposição do carvão em alcatrão e gases, é formada uma pasta que vai envolvendo as partes ainda sólidas, e outra parte que se agrega na estrutura metálica (denominada Jamb - Figura 3) e nas Portas de Operação.

Figura 3: Alcatrão no Jamb.

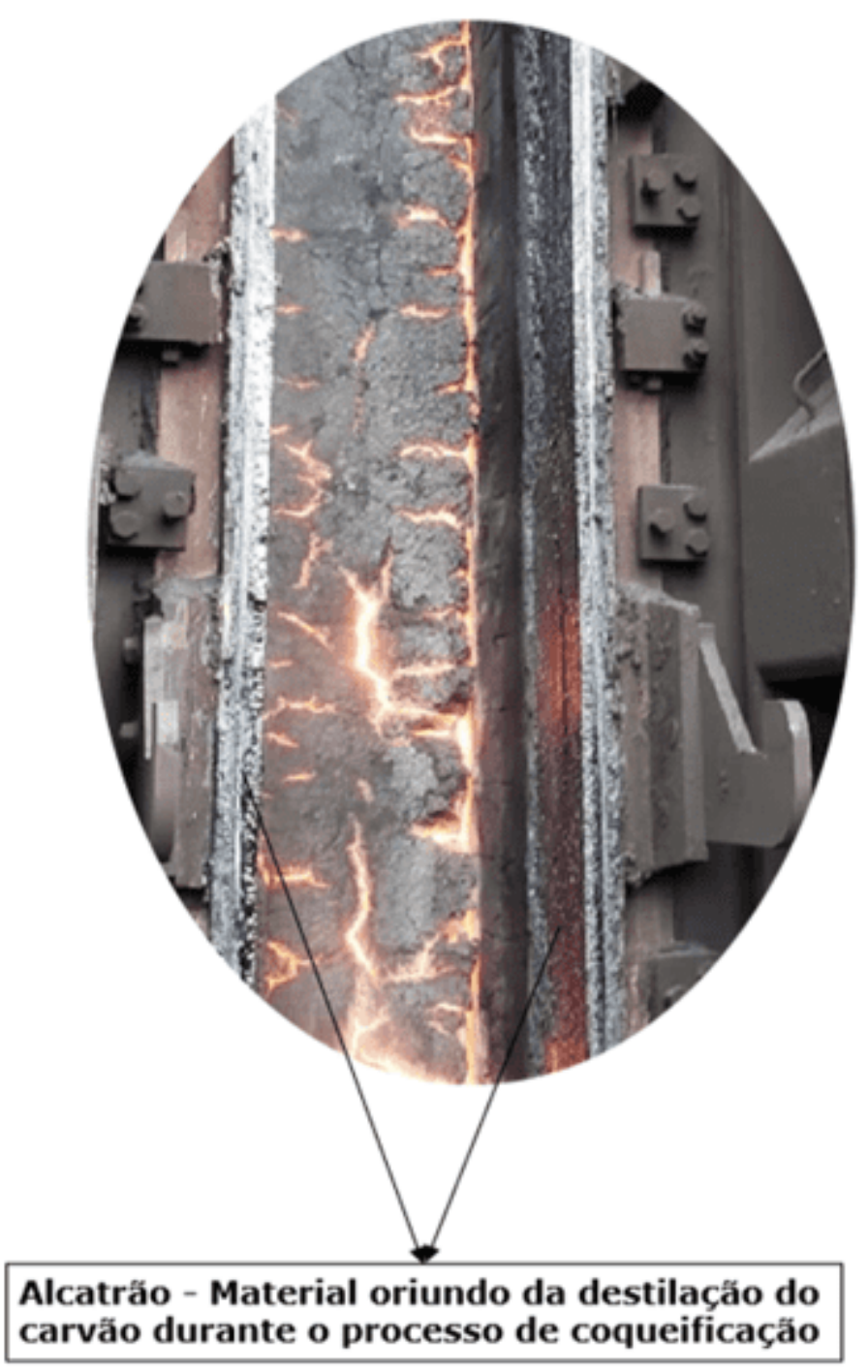

Fonte: Autor (2020). 
Após concluída a coqueificação do carvão, a remoção do coque de dentro do forno é realizada pela máquina desenfornadora, que através de um sistema eletromecânico, composto principalmente por um êmbolo, a massa de coque é empurrada para o outro lado. Por meio de um carro guia, todo o coque produzido é despejado no carro de transporte para apagamento (Figura 4). Após o desenfornamento, há a necessidade de limpeza das portas de operação (Figura 5).

Figura 4: Transporte de coque.

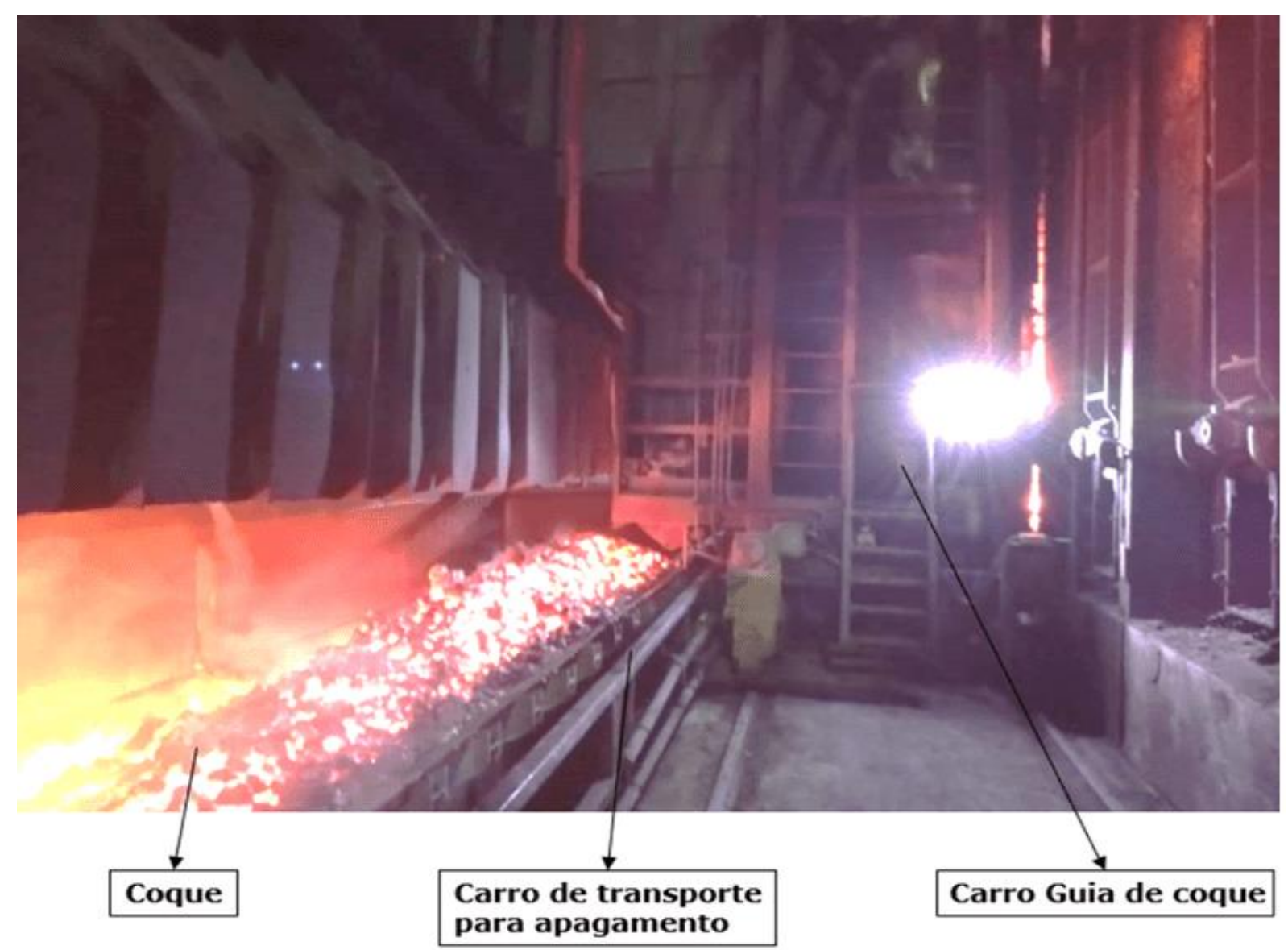

Fonte: Autor (2020). 
Figura 5: Limpeza manual do alcatrão.

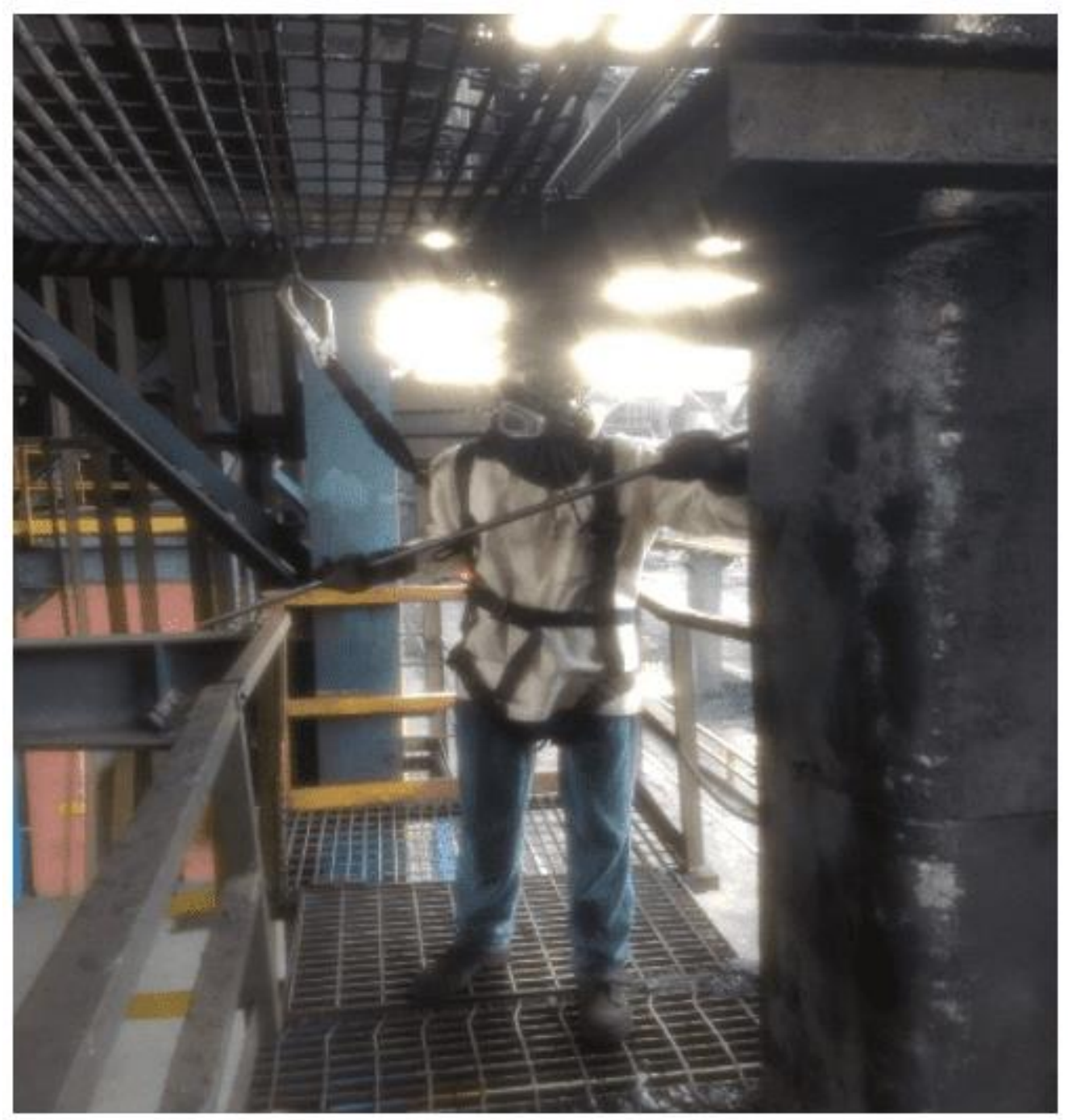

Fonte: Autor (2020).

Caso a limpeza não seja realizada pode ocasionar deficiência de vedação do forno. Para mitigar os severos riscos e eminentes danos ao equipamento e a integridade física dos colaboradores é necessário o correto gerenciamento dos riscos.

\subsection{RESULTADOS E DISCUSSÕES}

Os riscos associados à atividade de limpeza manual podem ser classificados de acordo com níveis (Figura 6). 
Figura 6: Quadro da Estrutura Analítica de Riscos (EAR).

\begin{tabular}{|c|c|c|}
\hline EAR Nível 1 & EAR Nível 2 & EAR Nível 3 \\
\hline \multirow{8}{*}{ Fontes de risco da atividade } & \multirow{3}{*}{ 1. Risco técnico } & 1.1. Eventual falha das ferramentas de limpeza \\
\hline & & 1.2. Risco de quebra da estrutura suporte da porta \\
\hline & & 1.3. Risco de danos no material refratário \\
\hline & \multirow{3}{*}{ 2. Risco de gestão } & 2.1. Falta de conhecimento do procedimento de limpeza \\
\hline & & 2.2. Eventual falha dos equipamento de proteção individual \\
\hline & & 2.3. Falta de treinamento em trabalho em altura \\
\hline & \multirow{2}{*}{ 3. Risco externo } & 3.1. Risco de paralisação das atividades por multas ambientais \\
\hline & & 3.2. Risco de contaminação da rede fluvial \\
\hline
\end{tabular}

Fonte: Autor (2020).

O gerenciamento de riscos de acidente da limpeza manual das portas pode ser realizado pelo diagrama Bowtie (Figura 7 ).

Figura 7: Diagrama Bowtie.

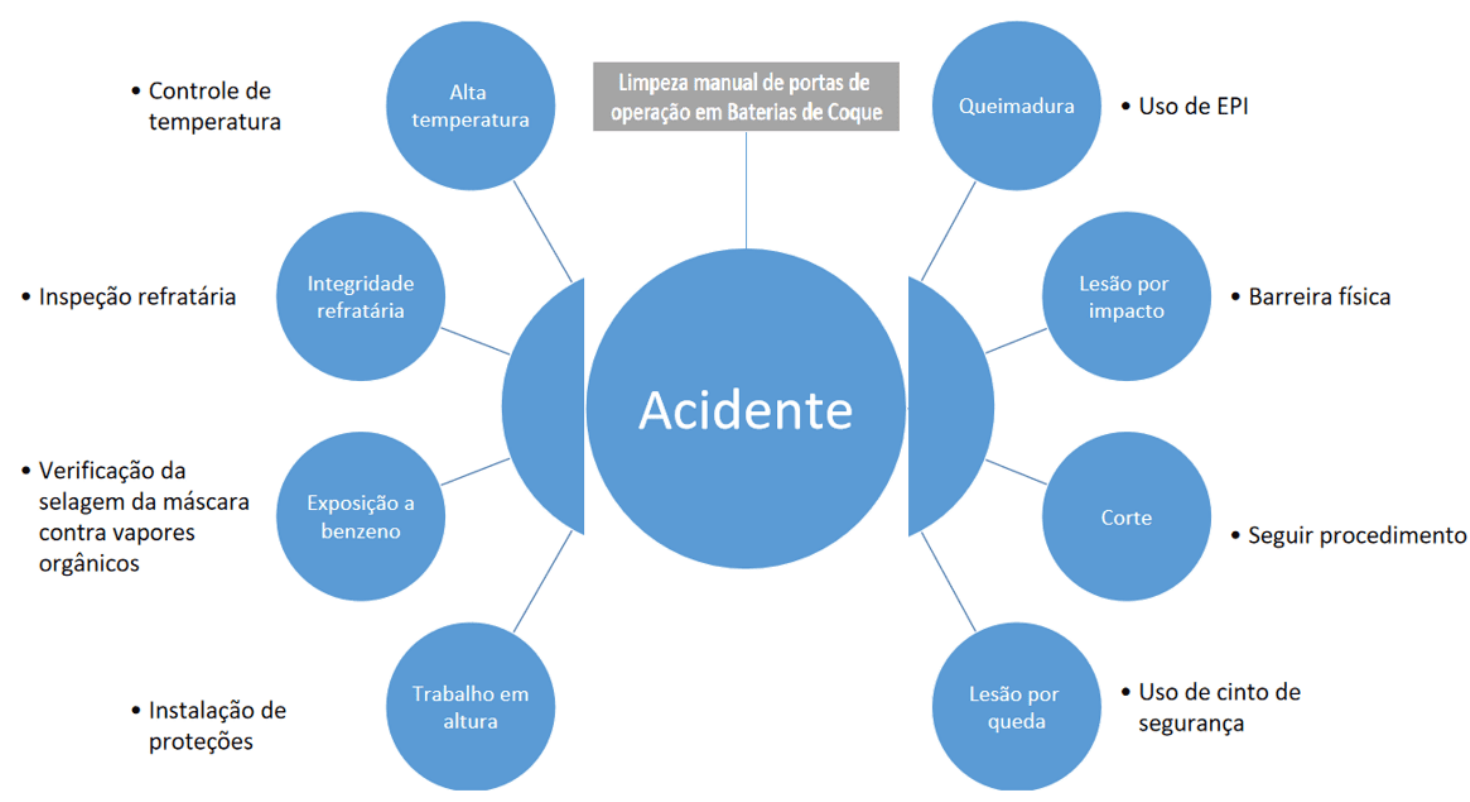

Fonte: Autor (2020).

Para reduzir riscos pode-se atuar em duas dimensões:

- Causas: as causas listadas do lado esquerdo do diagrama, representam as ameaças que a atividade expõe o colaborador, bem como as medidas protetivas para mitigação ou diminuição do risco. 
- Consequências: as consequências listadas do lado direito do diagrama representam a severidade que a atividade expõe o colaborador, bem como as medidas administrativas tomadas para mitigação ou diminuição da consequência.

No gerenciamento de riscos da atividade, os riscos são mapeados através da matriz de riscos (Figura 8), sendo apresentados os riscos associados à atividade de limpeza manual de portas operacionais (Figura 9).

Figura 8: Matriz de riscos da atividade de limpeza manual de portas operacionais.

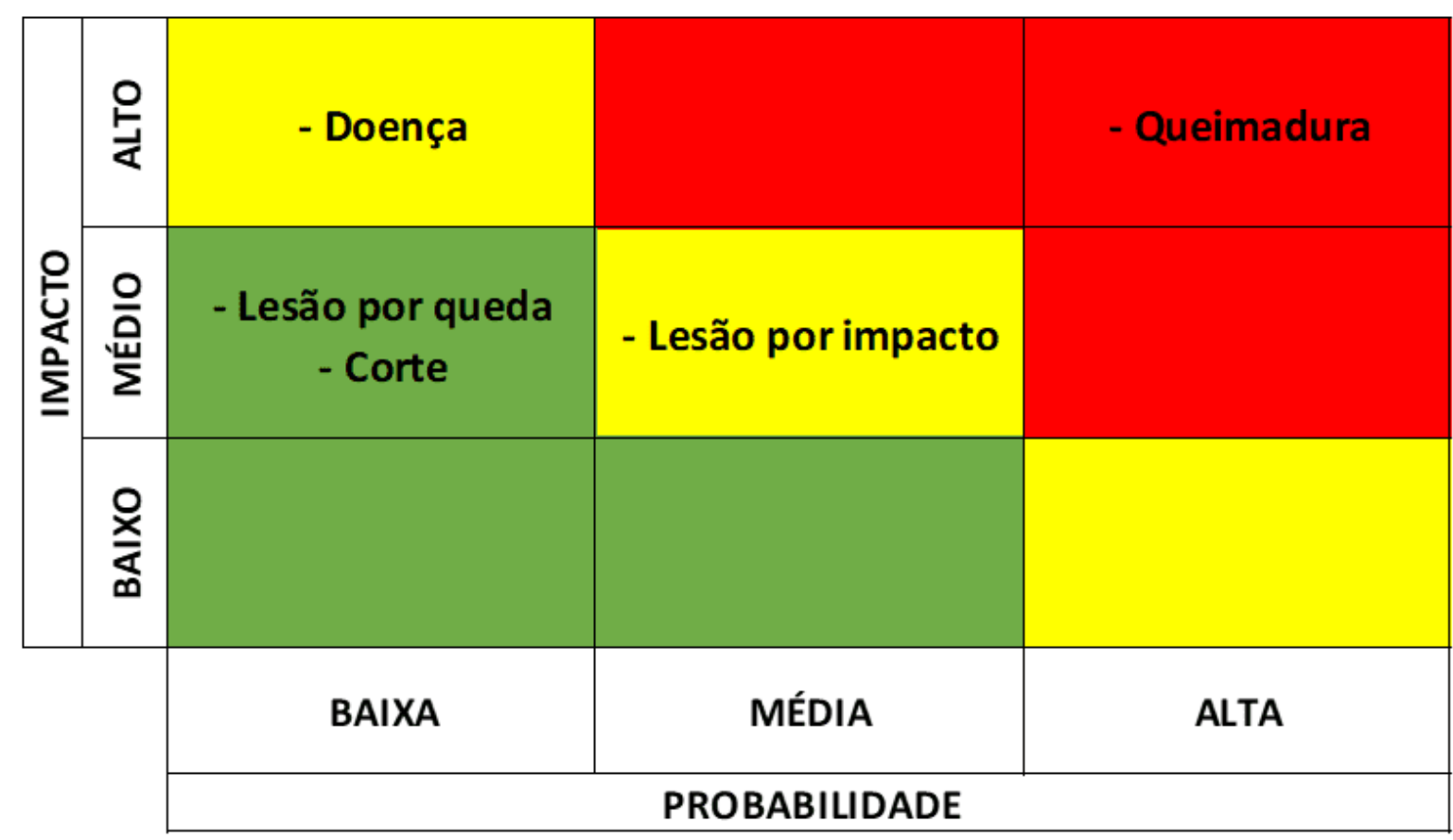

Fonte: Autor (2020). 
Figura 9: Matriz de riscos da atividade de limpeza manual de portas operacionais.

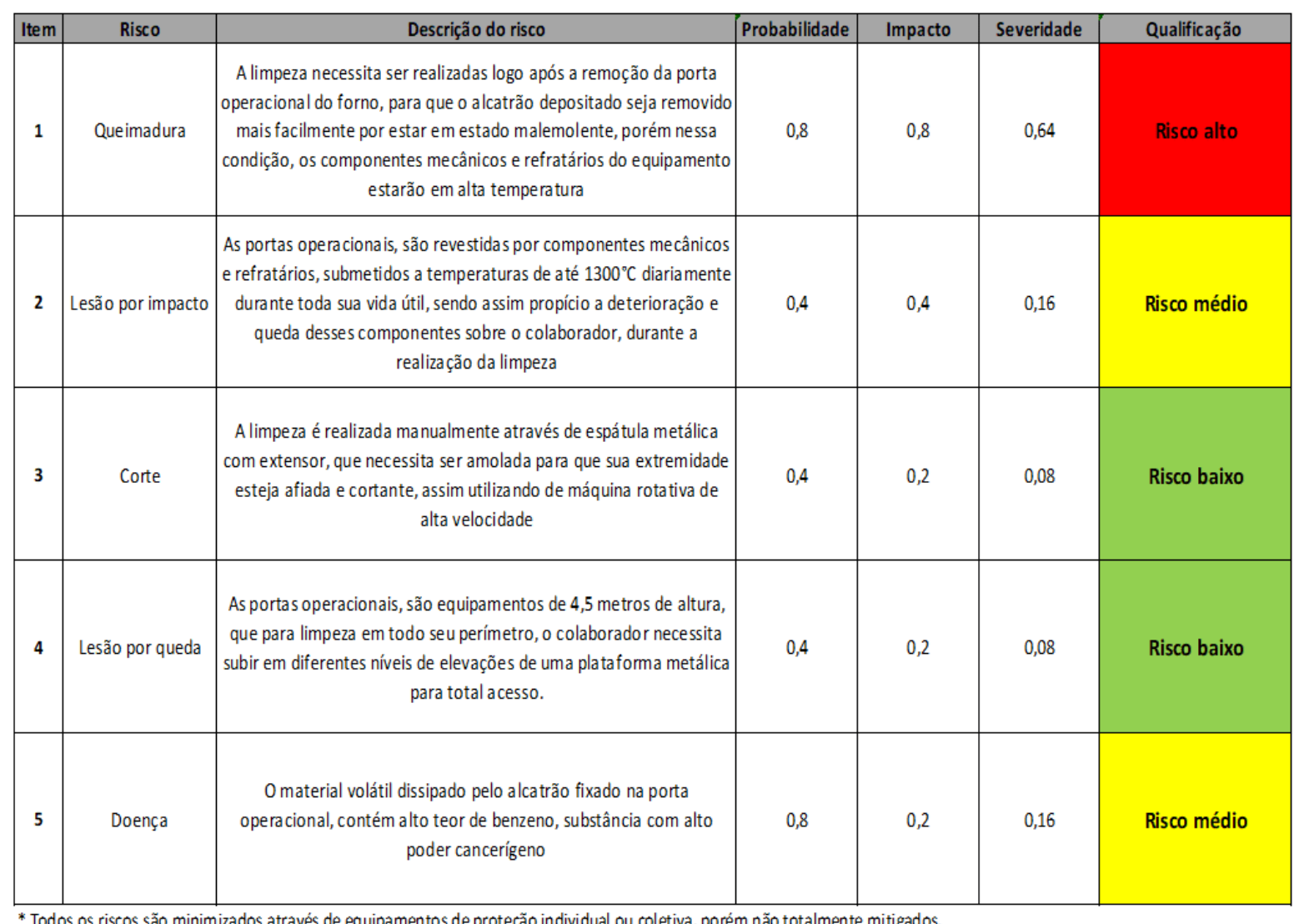

Fonte: Autor (2020).

Definidos os riscos e suas qualificações, deve-se abordar as estratégias de tratamento para cada um deles (Figura 10). Para o estudo em questão, pode-se tratar os riscos de acordo com as estratégias baseadas no guia PMBOK (2017). 
Figura 10: Estratégias para tratamento de riscos.

\begin{tabular}{|c|l|c|}
\hline \multicolumn{2}{|c|}{ Estratégia para tratamento de riscos } & Riscos \\
\hline Estratégia & \multicolumn{1}{|c|}{ Definição } & \multicolumn{1}{|c|}{} \\
\hline Aceitar risco & $\begin{array}{l}\text { Só haverá ação quando o risco se concretizar. } \\
\text { Normalmente usada para os riscos de menor grau. }\end{array}$ & $\mathbf{1 ~ - \mathbf { 5 }}$ \\
\hline Evitar risco & $\begin{array}{l}\text { Significa mudar o procedimento para n ã o ter nenhuma } \\
\text { chance de encarar a ameaça em questão. É uma alternativa } \\
\text { mais adequada para riscos de alto grau. }\end{array}$ & $\mathbf{2 ~ - \mathbf { 3 } \text { -4 }}$ \\
\hline Mitigar risco & $\begin{array}{l}\text { Transferir o risco para uma outra gestão, algo que pode ser } \\
\text { feito quando se trabalha em atividade que envolva } \\
\text { diferentes gerencias. }\end{array}$ & $\begin{array}{l}\text { Tentativa de reduzir o grau do risco. É uma boa alternativa } \\
\text { quando a mudança de planos representa uma perda muito } \\
\text { grande ou não seja possível. }\end{array}$ \\
\hline Explorar risco & $\begin{array}{l}\text { Usada quando se tem um risco de impacto positivo. } \\
\text { É focada em aumentar o grau do risco, para aproveitar as } \\
\text { oportunidades que podem surgir. }\end{array}$ & \\
\hline
\end{tabular}

Fonte: Autor (2020).

Diante dos severos riscos, eminentes danos ao equipamento e a preservação da segurança dos colaboradores, a implantação de um sistema que automatize a limpeza das portas das baterias de coque se mostra uma proposta altamente promissora, já que a vedação inadequada do forno pode acarretar consequências como:

a) Vazamentos de gases que entram em combustão e danificam os componentes mecânicos;

b) Ineficiência do processo de coqueificação, visto que o forno não estará hermeticamente fechado;

c) Danificação prematura dos tijolos refratários;

d) Escape de gases cancerígenos no ambiente. 
Para realização da limpeza das portas de forma eficaz, foi sugerida a implantação de um sistema automático (Figura 11) que aproveitasse a estrutura e recursos das máquinas desenfornadoras e carros guias para otimização e eficiência da limpeza.

Figura 11: Sistema de limpeza de portas.

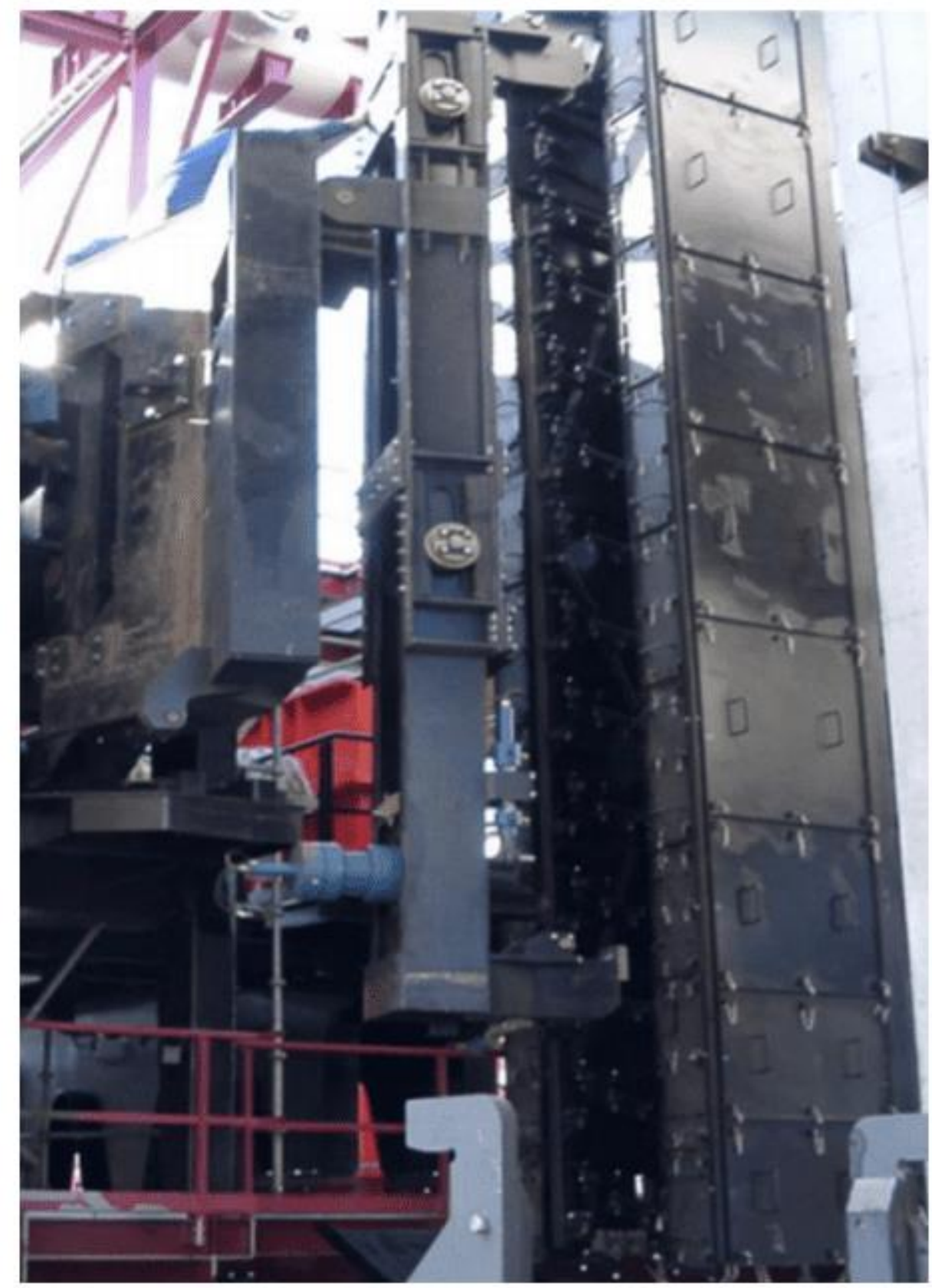

Fonte: Paul Wurth (2019). 
Alguns requisitos importantes relacionados ao escopo do sistema automático foram necessários para o projeto ser aprovado, sendo eles:

a) Garantir a realização da limpeza em todas as portas operacionais da bateria de coque;

b) A limpeza deve ser realizada em todo o perímetro da face de contato da porta operacional com o Jamb;

c) A limpeza deve ser efetiva o suficiente para remover todo alcatrão da face de vedação;

d) O sistema deve ter dispositivos de segurança suficientes para garantir a integridade dos operadores;

e) O sistema de captação de resíduos deve coletar $100 \%$ do material removido da porta operacional.

Os requisitos mínimos relacionados à qualidade necessária ao sistema foram:

a) O sistema deverá ser adaptado às normas brasileiras e padrões da siderúrgica;

b) Deverá ser contemplado o treinamento dos profissionais para operar o equipamento;

c) O equipamento deve ser fabricado com componentes de fácil obtenção em território nacional;

d) Deverá ser elaborado procedimento padrão para operação.

Após os requisitos serem cumpridos e os custos avaliados, o projeto foi aprovado trazendo melhorias do ponto de vista da segurança do trabalho, pois o trabalhador trabalha com menos exposição aos riscos. No quesito ambiental, a vedação das portas não está mais comprometida, e os gases não poluem a atmosfera, o risco de multas e até a paralisação da planta se tornam nulos, sem mencionar que a total 
vedação ajuda na preservação das partes refratárias, devido a interrupção de entrada de ar nos fornos.

\section{CONSIDERAÇÕES FINAIS}

Desenvolver o gerenciamento de riscos se mostra essencial para o sucesso do projeto. Com a utilização das ferramentas de gestão de riscos pode-se mapear de forma clara e direta os riscos associados às atividades e dar o direcionamento correto para resolver o problema. Com a gestão de riscos pode-se minimizar as chances de falhas, mesmo que existam riscos ocultos, a probabilidade de erros diminui consideravelmente.

Após a identificação dos riscos associados à atividade é possível desenvolver um projeto de implantação de equipamento para resolução do problema.

O projeto se justifica pela economia o qual irá trazer com a diminuição no custo de manutenção, a diminuição do risco de acidentes com colaboradores, mas principalmente com a continuidade operacional do equipamento por preservação das partes refratárias e eliminação de passivos ambientais que podem gerar multas e até encerramento das atividades.

Financeiramente 0 projeto não tem ganhos diretos significativos, porém o prolongamento da vida útil do equipamento, a preservação da saúde dos colaboradores, a interrupção da poluição atmosférica, que causariam multas e até a paralisação da planta, mostraram a necessidade de implantação do projeto.

\section{REFERÊNCIAS}

BARBOZA, Juarez. Consultoria \& Engenharia. Disponível em: $<$ https://consultoriaengenharia.com.br/>. Acesso em: 15/11/2020.

HARDARSHAN, S. V. (2014). Coke Production for Blast Furnace Ironmaking.

LEWIS, S. and HURST, S. (2005). Bowtie an elegant solution? - Strategic Risk. 
PADOVEZE, C. L. (2010). Contabilidade Gerencial: Um enfoque em sistema de informação contábil. 7. ed. São Paulo: Atlas.

PADOVEZE, C. L. (2009). Controladoria Estratégica e Operacional. 2. ed. São Paulo: Cengage Learning.

PMBOK, 6 ${ }^{\text {a }}$ edição, 2017, PMI, Guia do Conjunto de Conhecimentos em Gerenciamento de Projetos.

RAMOS, C. H. F. (2009). Análise de risco empresarial. Santa Catarina: Qualytool.

ROVAI, R. L. (2005). Modelo estruturado para gestão de riscos em projetos: estudo de múltiplos casos. 2005. 364 f. Tese (Doutorado em Engenharia de Produção) - Escola Politécnica da Universidade de São Paulo, São Paulo.

Enviado: Novembro, 2020.

Aprovado: Janeiro, 2021. 